Peterson, E., \& Kempf-Leonard, K. (1999, September). A Matter of Life And Death: The Failure Of Juror Instructions In Capital Cases. Justice Professional, 12(2), 173.

The published version is available through Taylor and Francis/Routledge at http://www.routledge.com/.

\title{
A Matter of Life and Death: The Failure Of Juror Instructions In Capital Cases by Elicka S.L. Peterson
}

\begin{abstract}
:
Findings based on interviews with capital jurors indicate that considerable confusion exists over sentencing instructions. Jurors had difficulty understanding the content of the instructions, sometimes disregarding them altogether. Jurors placed a premium on remorseful demeanor from the defendant, and this weighed heavily in their sentencing deliberations. Many jurors who chose the death option misunderstood the true meaning of a life sentence. Finally, grave concerns were expressed about the competency of other jurors. In light of these findings, we call for the adoption of a priori training and better juror instructions based upon Gottfredson and Gottfredson's (1980) model for rational decision-making.
\end{abstract}

Keywords: Juror instructions; capital cases; rational decision-making; capital jury project

In 1972, the U.S. Supreme Court ruled in Furman v. Georgia that death penalty decisions were "arbitrary and capricious" because the juries in capital cases had too much unstructured discretion. Officials of state governments then attempted to remedy this situation by responding with various instructions, guidelines, and mandates for sentencing decisions for which the life of the defendant is at issue, but no single method has been endorsed (Bowers, 1995). The difficulties also have not been resolved, as evidence of harmful disparities continues to be reported (Baldus, Woodworth, and Pulaski, 1990; McCleskey v. Kemp, 1987), and may, in fact, have worsened because the number of defendants sentenced to death in recent years has escalated and strides have been made to limit the opportunities for appeal (American Bar Association, 1997a,b). In this article, we present evidence that jurors who serve on these important cases misunderstand both their responsibilities and the procedures available to them. Drawing on effective reforms in other areas of criminal justice and the theory of rational decisionmaking, we offer recommendations to educate future jurors better and to structure the 
decision process they use. We argue that these recommendations would result in more consistent and equitable outcomes.

We turn first to the general criticism on how criminal justice operates in the United States offered by Michael and Don Gottfredson's because, although they did not specifically mention capital cases, their concerns also seem to apply to jury decision-making in death sentences:

... decisions are not always highly visible. They are made, ordinarily, within wide areas of discretion. The aims of the decisions are not always clear, and, indeed, the principal objectives of these decisions are often the subject of much debate. Usually they are not guided by explicit decision policies. Often the participants are unable to verbalize the basis for the selection of decision alternatives. Adequate information for the decisions is usually unavailable. Rarely can the decisions be demonstrated to be rational (Gottfredson and Gottfredson, 1980, p. v).

To overcome these problems, they recommended adopting a rational decision-making approach to criminal justice. They argued that important case processing decisions should include ( 1) an agreed upon objective, (2) viable alternatives, and (3) adequate information on possible outcomes with which to evaluate the options.

They elaborated on this simplistic model of rational decision-making to include the following seven additional requisites for ideal criminal justice processing:

(1) the decision structure should have some flexibility to consider unique case factors;

(2) discretion should be controlled, however, to promote consistency across decisions;

(3) a clear distinction should exist between general policy and individual case decisions;

(4) the policy and decision rules should be stated clearly;

(5) routine feedback mechanisms should help inform decision-makers;

(6) adequate measurement and classification of key decision criteria is essential; and

(7) the process should evolve based on information generated from earlier decisions.

Although not prerequisite to their decision model, the Gottfredsons further articulated "guideline instruments" as the preferred method to implement good decision models and many such instruments have been adopted. Pioneered for parole supervision

(Gottfredson, Wilkins, and Hoffman, 1978), guidelines instruments are now probably the 
most common in guiding sentencing (Frase, 1995). These instruments also assist in pretrial decisionmaking (Goldkamp and Gottfredson, 1985; Jones and Goldkamp, 1991), institutional classification (Brennan, 1987; Sechrest, 1987), and have most recently been touted for the full spectrum of juvenile case processing (Bonta, 1991; Weibush, Baird, Krisberg, and Onek, 1997).

Given the wide implementation, and thus exceptional promise bestowed on the decision model advanced by Michael and Don Gottfredson, it is remarkable that neither their theory nor the guidelines method have been applied to death penalty decisions, which are arguably the criminal justice decisions of greatest consequence. Perhaps this situation exists because the Gottfredsons offered no specific concerns about death penalty cases or jury decision-making, although they did present their model as generally applicable across criminal justice. The more likely reason, however, is the melange of directives for capital cases contained in a series of U.S. Supreme Court rulings.

The mish-mash of decisions probably began in 1971 with McGautha v. California in which the Court ruled that statutes need not, and indeed probably are incapable of, guiding capital juries. In the landmark Furman v. Georgia decision the following year, however, the Court called jurors' unguided discretion "arbitrary and capricious," resulting in death penalty decisions paramount to violations of constitutional prohibitions against "cruel and unusual punishment." When states responded to the Furman decision with a variety of new regulating statutes, the Court rejected mandatory death penalties, ruling in 1976 decisions on Woodson v. North Carolina and Roberts v. Louisiana that capital cases require "individualized treatment." Also in 1976, however, in decisions on Gregg v. Georgia, Proffitt v. Florida, and Jurek v. Texas, the Court endorsed "guided discretion" bifurcated the process for the guilt and punishment decisions, and ruled that the new statutes could, and probably would, remedy problems of unconstitutional arbitrariness. The Court then contradictorily promoted deregulation in the Lockett v. Ohio decision in 1978 that guidelines must not restrict jurors' consideration of mitigation and the Zant v. Stephens decision in 1982 that it is not necessary to restrict their consideration of aggravating factors. In 1991, in Payne v. Tennessee, the Court expanded the range of acceptable aggravating factors to include the character of the victim as well as the impact of the crime on the victim's survivors. In 1994, the Simmons v. South Carolina decision noted the right of a defendant in a capital case to have the jury accurately informed about the sentencing alternatives, and thereby the Court, itself, acknowledged some difficulty in capital jury decision-making. The inconsistencies across these, and other, decisions of the Court led William Bowers to conclude: "Indeed, the Court's decisions have affirmatively forsaken any model or legal formulation as to how the decision should be made" (1995,p. 1067). In his dissenting opinion in Callins v. Collins in 1994, the Courts legacy also led Justice Blackmun to comment that "the death penalty experiment has failed."

This article examines how jurors interpret their responsibilities in capital cases and how the decisions are made. We use the Gottfredson's decision model to interpret the data we obtained for Missouri as part of the Capital Jury Project. Given our findings, we are able to conclude with specific recommendations for how these very important decisions might be improved not only in Missouri, but also more generally in capital cases. 


\section{RESEARCH DESIGN}

As part of the Capital Jury Project,[1] the data for this research are drawn from lengthy interviews with 56 individual jurors who together served on 19 capital cases in Missouri between March, 1989 and July, 1995. The cases include roughly equivalent numbers of life and death sentences and each case is represented by between two and five jurors. In each of the 19 cases, following the decision on guilt, the jury was restricted to choices between sentences of death and life in prison without parole. Juries were given written instructions tailored to the individual case that directed them about weighing consideration of aggravating and mitigating circumstances and the available options.

From a list of all recent capital cases in the state, efforts were made to identify all jurors for all cases through contacts with courts, attorneys, and media. In some jurisdictions we were able to identify names of jurors, while in other locations no such lists were available, and juror identification was prohibited by court-order in a few circuits. Our exhaustive efforts yielded a total of 21 cases, including 11 with life sentences and 10 with death sentences. Sample cases are geographically distributed across the state, although disproportionately more are from the St. Louis region, as is true of the population of capital cases.

We attempted to contact the former jurors with letters and phone calls based on information obtained from telephone directories from across the state. Often we succeeded in locating the juror immediately, in other cases it took several attempts, and in some cases the juror was never located. Once located, most jurors agreed to participate in the face-to-face interview, but some refused. Five jurors agreed to be interviewed, but did not allow the interview to be recorded. Two cases were eliminated because we could not interview multiple jurors. Although the case was identified, juror identity was not recorded on the data collection instrument.

Data collection followed the structured questionnaire schedule adopted by the Capital Jury Project in 1991 (see Bowers, 1995). The instrument separately inquired about the guilt and penalty phases of the trial and included many checks on the internal validity of the responses. Interviews lasted between four and six hours, depending upon the level of detail and elaboration provided by the juror. We provided \$20 as a token of appreciation for their assistance.

\section{FINDINGS}

Among our 56 jurors, 55 percent were women, 71 percent were married, 70 percent had children, and 92 percent were white. The median age was 47, with 10 percent each younger than 30 or older than 60 . Nearly half were college graduates, 25 percent had attended some college, and 25 percent were high school graduates. The median annual 
income was between $\$ 30,000$ and $\$ 50,000$, and 88 percent were homeowners. Sixty-nine percent worked full-time, another ten percent each were homemakers, retired, or parttime employees. Less than half were daily newspaper readers, although 77 percent reported listening to the radio or television on a daily basis. Only 20 percent had any prior jury experience.

Two-thirds of the jurors remained "absolutely convinced," and 18 percent were still "pretty sure" of the defendant's guilt. Only 45 percent, however, were "absolutely convinced" and 16 percent were "pretty sure," that the jury's punishment decision was correct. Following their experience, twenty jurors "strongly agreed that the death penalty is too arbitrary because some people are executed while others serve prison terms for the same crimes." Most importantly, eleven jurors directly noted their difficulty understanding the instructions to the jury, and one-fourth of those interviewed reported wishing they had done something differently as a juror.

To gain specific insight into the juror decision-making process and the particular difficulties they encountered, we turn next to actual comments made by jurors during the interviews. Although they are not chosen at random and we have arrayed them to present our arguments, these qualitative accounts do represent a cross-section of all the jurors and are verbatim as delivered.

\section{Jurors on Their Overall Performance}

According to their initial comments, jurors thought they, and the jury on which they served, were competent and conscientious, although many subsequently raised serious concerns throughout the interview on specific issues related to how well jurors fulfilled their mission. Given the gravity of the task, this positive view of the job done by the jury seems understandable, and there were many points in the interviews where jurors appeared to be reassuring themselves that they carried out their duties correctly:

I'd have to say the jury I was on did a great job, overall. We really took it serious.

Everyone was really concerned that we do it right, and I think we did. There was only one guy who seemed mostly interested in getting done quick so he could get home, and the rest of us just tried not to let it bother us.

It wasn't like the O.J. Simpson case. We really looked at all the evidence. We weren't his peers--I mean, how can you say you're a peer of someone who shoots someone in the head twice, but we were definitely fair. We definitely considered everything we were supposed to.

Although this overall assessment of juror diligence might lead one to the conclusion that all is right in the capital sentencing process, other comments made throughout the interview give pause. As we examine juror perceptions about the efficacy of sentencing instructions, a very different picture begins to emerge. 


\section{Jurors on Capital Sentencing Instructions}

Some jurors indicated that they had little or no difficulty understanding and applying the sentencing instructions provided. However, very few remained consistant in this assessment throughout the interview. Thus, jurors often began with a positive statement upon direct questioning about the instructions, only to elaborate on difficulties related to the instructions during questions about the sequence of events leading to the sentencing decision, jury interaction, and dealing with dissenting opinions:

I'd say there was a fair amount of discussion regarding the instructions ... it was the leader of the group who wanted to make sure everyone understood everything.

I could follow them [the instructions] very easy, and the way they stated everything, from what we all felt about the evidence, I mean it's just like you just take it straight down the list...

... They give you this printout sheet ... it's just like a piece of paper, they don't explain it or anything, and it says you should think this and you should do this. That's basically what it says. There's not too many choices here. There's "A" then "B" and that's basically what it says. You gotta just pick.

They gave us very vague instructions.

I don't specifically remember anything about her [the judge's] instructions.

They were very helpful. I mean, we read and re-read them

Taking notes helped a little, but even though it was a short period of time, there was so much thrown at you at one time.

... We got a little booklet that told us, there's like step-by-step instructions. I can't remember much of 'em--but, like, you can't use alcohol or alcoholism as a vice in making a decision. Other than that, there wasn't really anything that sticks out that you couldn't use in your deliberation.

I don't ever remember discussing anything about what the instructions were. I mean, we all knew what the possibilities were: If we found him guilty of first degree murder, it was gonna be life in prison without parole or the death penalty, because that was gone over. The instructions were just those two basically. Umm, that's what it boiled down to except if you can't find him guilty of first degree murder, then you can find him guilty of second degree murder, or he can be innocent. I don't think there was anything like manslaughter ... I think that's involuntary, and this guy volunteered [so it wasn't applicable]. 
... I was pretty sure [in the guilty phase], I mean, I was gonna look at some of the evidence, but I had a pretty good feeling when I went in there [to deliberate] unless someone could point something out to me, and really the only evidence the instructions said to dismiss was the fact that he had been drinking ... that was the only deliberated part, and we basically got to throw that out.

An alarming number of jurors indicated that there were problems related to the sentencing instructions provided by the judge in terms of the juries' inability to understand the semantics of the written instructions. Many commented that the "legalese" made things more difficult, some thought the instructions were too vague, and several clearly never understood the guidelines:

The instructions made it harder ... they didn't make a lot of sense. We had problems with a lot of the ways things were worded. It was a pretty vulgar crime, but was it heinous or whatever?--And the second part of the question--we had to agree to both parts--was whether we believed the defendant caused physical pain and emotional stress with the intent to make the victim suffer. Well, there was no proof of that ... the foreman would say, 'Here, read it.' They wouldn't read the instructions. They just flat-out refused to look at the papers. They'd say, 'Fine, we'll let the judge make the decision.' But if you read the wording, the judge doesn't make the decision. If we couldn't agree to a decision, it says he gets life. It was just ugly.

[the judge's instructions to the jury were] We would find all the answers contained within the juror's instructions. We were all ticked off as we are not attorneys. [A juror] had a bunch of attorneys in her family and I don't even think she knew what the hell this stuff was. And it wasn't explained to us, and that was the most important thing. Not until afterwards ... the way this stuff is worded is that way because it's how the books told them they have to word it. But that wasn't told to us ... we're sitting there thinking, "Oh, they tried to trick us."

There was a little bit of impatience because some of the people just didn't seem to understand the way it's worded. The instructions they give you were just ... you know, you figure they're picking the common man for jury duty, and they're not picking all college educated people, because obviously that would not be a jury of your peers. And a lot of these people just did not know what the heck this stuff meant, and it was frustrating trying to get it across to them ...

The prosecutor never did tell us his [the defendant's] motive for the murder, and I don't know if that was something he couldn't tell us--whatever the rules of the court were. Apparently there were quite a few of them ... what's admissible--what's not. The motive probably wasn't important ...

They explained it before we went in and it was also in the little deal they gave us. I mean they gave us a little pamphlet. There was a portion in there that made it clear: It [the sentence] was definitely death without parole. 
Clearly there are problems with the existing instructions for juror decision-making. In addition to these problems, however, we encountered a far more alarming finding in that some jurors professed to disregard these instructions in favor of a sentence they believed "just made sense"

\section{Jurors on Disregarding Instructions}

A few jurors mentioned situations in which sentencing instructions were disregarded entirely, although none went so far as to say that this action was willful. Often, this seemed to occur in the context of a sentencing decision that was intuitive to jurors, and thus one that, in their estimation, would only be confounded by applying the guidelines:

Those instructions from the judge just gave us a framework to make the decision that we had already made.

We were told to dismiss the instructions.

I'd say the one thing I can fault our jury for is that they didn't follow the judge's instructions about refraining from discussing the case prior to deliberations ... I think that's a human nature thing ... I think people just couldn't stop themselves. They should just take that one out ...

Although there were few cases reflecting this disregard for juror sentencing instructions, this finding is still alarming. Another cause for concern is found in the one characteristic of defendants routinely named as most important to jurors: affect.

\section{Jurors on Characteristics of the Defendant}

The majority of jurors demonstrated strong feelings about the defendants, particularly in terms of their demeanor. The defendants' display of remorse, or lack thereof, was tantamount in jurors' impressions, and weighed heavily in deliberations:

He [the defendant] didn't have any emotion at all 'til the sentencing portion of it, and we talked about that a lot. You know, he didn't testify.

He didn't show any emotion--he had that "guilty" look.

He basically just seemed like he wasn't even there, you know? Like he was just sitting there. He had very little if any emotion at all on his face. We didn't see any until the sentencing hearing when his mother got up on the stand. He looked at us a lot, but it wasn't menacing. He made eye contact with some jurors. 
What might have changed your mind about what the punishment should be? Probably if he showed more remorse for the crime or there was some circumstances that didn't make it so vicious. He was cold--we all thought so ... one cold customer.

His basic mood was no emotion at all ... his eyes didn't roll when things were said--he just pretty much sat there. Didn't do anything. I mean, there was no emotion when the guilty verdict was read on murder one.

What would most help you decide "whether there is a probability that a defendant would commit criminal acts of violence that would constitute a continuing threat to society?" I have no idea. Mostly their attitude. If they don't show remorse or sorrow, what will stop them from doing it a next time? That's pretty much how we [the jury] figured it.

He never said he was sorry.

He was really kinda emotionless throughout the whole thing. He was attentive, as far as paying attention to what was going on. That's why I don't think he was bored ... but he didn't react at all ... it gave us all the creeps. He was expressionless. I didn't get the impression he was sorry, you know?

He was a non-entity: no reaction, no remorse, no anything.

Judicial instructions not to consider defendants' lack of testimony on their own behalf were mentioned by several jurors. The majority of jurors said they took this instruction seriously, and were unaffected by a defendant invoking his or her right not to testify, but a few jurors mentioned this lack of participation in the context of a cold, detached impression:

[In a case in which the defendant did not testify] Uh, I don't think I allowed it to make much of an impression at all because the judge was very specific in directing us. I didn't really take that into consideration--I tried to just listen to what, you know, what we were presented with. He probably would have hurt his own case.

I didn't think about it [the lack of testimony] when I was making my decision, because he didn't seem too involved ... I can't see this guy caring enough to get up there ... he was like a machine.

It is disturbing to consider that a defendant's facial expression weighs so heavily in the balance of life or death. It is even more disturbing to find that jurors who issued death sentences reported that they did not feel they had adequate information about the alternative to the death penalty to feel comfortable selecting that option.

\section{Jurors on the Meaning of a Life Sentence}


There was considerable confusion over the parameters of a life sentence among the jurors interviewed. In some cases, this confusion resulted in the idea that a death sentence seemed the safer choice in terms of public safety. Indeed, this widespread uncertainty is troubling in its distribution: Only jurors from cases resulting in a death sentence expressed this confusion about the possibilities for parole and overall length of the alternative sentence:

We weren't sure when he'd get out if we gave him life ... I think it's life in prison [if not the death penalty]--well, probably twenty-five years--unless they say life without parole, cuz' then you can't get out.--I think.

I think they spend the rest of their life in prison. There's no parole for them.

What were the strongest factors for and against the death penalty? For was that he would not murder anyone else. Against was that he would be in prison living happily ever after-for awhile. There was nothing to debate.

My problem [with giving a life sentence] was that life without parole--even though they told me no parole--I had my doubts. He'd get let out.

If it was capital murder, he could get death. I don't remember the exact alternative with life. There was some confusion over whether life really is life.

What do you remember about the judge's instructions to the jury for deciding what the punishment should be? Well, that for him to get the death penalty--that we really only had two choices: either life imprisonment or the death penalty. --And that everyone had to agree on the death penalty or it would automatically become life imprisonment. [to interviewer] By the way, do you happen to know if life really means they're in prison for the rest of their life--no matter what?

What were the strongest factors for and against a life (or alternative) sentence? I think I thought really more in terms of "for or against the death penalty." I didn't really think about it much.

Obviously, this finding suggests that jurors need more information with which to make this decision, especially as it seems intuitive that a sentence they are sure of will be chosen over an unknown alternative in most cases. The fact that every juror expressing confusion sat on a case resulting in a death sentence seems to support this interpretation. Finally, jurors made many comments about juror competency that suggest change as well.

\section{Juror Concerns about Juror Competency}


While initially expressing a positive opinion about the competency of jurors, many disturbing concerns emerged at various points in the interview that add credence to the call for offering jurors more assistance in making this difficult decision:

I've tried to block most of the events out of my mind. I didn't like having been made to decide on death as the penalty.

I think some people just really weren't honest about their feelings about the death penalty just to get on the jury.

We had a couple of people on the jury that were just wimps and should not have been there. They just couldn't make the decision. It was really awful--they cried and everything.

Can you think of anything else we haven't talked about that would be important in understanding the jury's punishment decision? I would say that most of the people on there [the jury] were straightforward law and order type people. Pretty conservative-definitely--if you commit the crime, you need to be punished. Not really the types to be looking so much for reasons to understand necessarily why a person would find themselves in that kind of situation.

Did you find the experience emotionally upsetting? Yes. It's real hard to make a death decision. I felt not qualified to make a death decision. They should pay or hire qualified jurors.

I've even had second thoughts, I mean, over the years. I wouldn't even know who to contact--I mean, his case really needs to be looked over carefully. I don't know the status of his case at this point--if he's still on death row or what.

This'll sound bad, but the judge called us in and asked us if we wanted to call it a night, and basically, we told her we wanted to get it finished. We all wanted to get it done and go home. At that point it was nerves--gut wrenching, I guess, but we didn't want to be there another day ... we just had to come up with a something they [those leaning toward life] could live with.

The worst part about it [being on the capital jury] was having to go through having to actually make a decision about someone's life. You're God. At that point in time, your decision, um, that was what was going to happen to that person.

At the guilt phase, did jurors discuss whether the defendant would get the death penalty? See, it wasn't really spoken, but there was definitely a subtext there. I mean, that certainly was always a factor I believe was in people's thoughts, and I think they only stayed away from discussing it at this phase because the judge had been very good and clear in terms of instructing us. But I think there were definitely people on the jury that were very adamant that he should die from the very first piece of evidence--that's how strongly they felt about the death penalty. 
Anything more about the jury that explains how or why it reached it's decision [in this case, death]? There are strong people and weak people. The strong people will win. If the jurors had felt otherwise, there would have been a hung jury.

The sentencing part was so emotional ... dealing out someone's future like that. We did a good job, though.

Some people just wanted their own way. They seemed like they just knew from the beginning that they wanted the death penalty ... but most of us weren't like that.

Can you think of anything else we haven't talked about that would be important in understanding the jury's punishment decision? I think that a fairly substantial number of people had really strong preconceived notions about the death penalty that they didn't necessarily fully reveal during the jury selection. I think that they were dishonest, and that they were probably more strongly in favor of the death penalty than the impression they gave the attorneys during that selection, because they were, you know, so adamant about it the moment we went in for deliberation. There wasn't even a discussion for some people--they were just like, well, that's what the punishment should be. People began to express their opinion on it when they were trying to force the one woman into voting for it.

In sum, jurors themselves expressed (or cast) grave doubts about the competency of jurors to handle this important decision, at least given the assistance they currently receive. In the following section, we speak to these concerns in offering a framework in which to overhaul the process of aiding capital jurors in making fair, rational decisions.

\section{IMPLICATIONS AND RECOMMENDATIONS FOR IMPROVEMENT}

So, what light do these findings shed upon the problem of capital jury decision-making? Clearly, the current means of instructing jurors leaves much to be desired, but what can be done to rectify the situation? We believe that the answer lies in the application of new procedures for instructing jurors based upon the tenets of Gottfredson and Gottfredson's (1980) rational decision-making model.

In Furman v. Georgia, the Supreme Court ruled that the decisions of capital jurors were arbitrary and capricious to the point of unconstitutionality, and that unless this situation improved, application of the death penalty itself was unconstitutional. Gottfredson and Gottfredson's (1980) call for a decision structure with sufficient flexibility to allow for individual factors, while controlling discretion enough to promote consistency across decisions provides a tool to address the Court's concerns. We suggest embedding this structure in an ongoing program designed to promote rational, equitable decision-making by jurors on capital cases. This juror education program would include a short class, clear written guidelines, and an ongoing feedback mechanism to develop jurors' ability better to serve the court. 
The qualitative data from the Capital Jury Project in Missouri suggest that the vast majority of jurors take their duty seriously, and wish to make the best choice possible in a situation they do not take lightly. Given this motivation and respect for the importance of their task, coupled with their concerns about their own competency in handling this matter, we believe that jurors would respond very positively to efforts to help them in their endeavor. The program to accomplish this task should be far-reaching, but we believe it can be accomplished with a modest investment of personnel and resources, even in smaller venues.

The first step in the juror education program would be a one-to-two hour class administered by someone specifically trained for the task. This class could be administered to the jury pool and would help fill the unoccupied time many potential jurors experience while awaiting actual jury selection. This class would serve to inform jurors chosen for capital cases about the responsibilities before them, and would provide a detailed review of the written guidelines for decision-making. Potential jurors would have the opportunity to clarify any points of confusion and ask practical questions about the trial process and what their part would be in it. Although the written instructions might not be allowed in the courtroom, jurors would still benefit from having knowledge of them throughout the trial, rather than at the conclusion of each stage. This would aid in sorting and evaluating the vast information presented to them during the proceedings.

Our findings clearly indicate that the actual written instructions for jurors must be revamped to include less legal jargon. A panel of Legal, and English language scholars should be formed to create the initial document, with feedback on its accessibility coming from a series of focus groups consisting of a representative sample of registered voters. In this manner, the legal tenets necessary, coupled with the decision-making tenets from Gottfredson and Gottfredson's (1980) framework can be combined in a document that is easy for laypersons to understand and incorporate.

The final step in this new process for instructing jurors on decisionmaking involves a continuing source of feedback about the results of this method of juror education. Jurors would complete a brief exit interview consisting of questions about everything from the ease of understanding the instruction documents, to specific questions about sentencing options and other more concrete information about the capital case process. In this manner, the methods in which jurors are prepared to make this important decision can be periodically re-evaluated and improved upon when necessary.

These three steps incorporate most of Gottfredson and Gottfredson's (1980) rational decision-making criteria. Further, the Gottfredsons' proposal that the policy and decision rules be stated clearly would be served by a thoughtful revision of the juror's instructions, as well as the requisite class. If implemented in a thoughtful manner, this method of instructing the jury should allow flexibility, but promote greater consistency across capital verdicts. Thus, arbitrary and capricious outcomes should be reduced, in accordance with the Supreme Court's determinations. 
Moreover, Gottfredson and Gottfredson's (1980) rational decision-making requires a clear distinction between general policy and individual case decisions. As applied to deciding capital cases, this would be facilitated by the requirement that jurors submit a brief, written explanation of the factors they considered in their deliberations. Obviously, jurors could still be less than forthcoming in identifying extralegal factors such as the demeanor, class, or race of the defendant, but this is less likely in a group setting, especially given that all jurors would be required to conspire to misrepresent the substance of their discussion. We believe it would be more likely that jurors, knowing that they will be required to account for the substance of their discourse during the decision-making process, would make an extra effort to consider only relevant factors, and present as fair a decision as possible. To bolster this effect, all jurors would be required to sign this explanation form.

The newly formulated guidelines and exit interview should satisfy the Gottfredsons' (1980) requirement of adequate measurement and classification. Our findings indicate that concepts such as "heinous" and "life in prison" must be explained in a much clearer manner. Additionally, measurement of the success of the classroom instruction and guidelines is facilitated through questions in the exit interview.

Finally, according to the Gottfredsons, the process should evolve based upon information generated from earlier decisions. Again, the exit interview, coupled with ongoing criminological research into the equity (or lack thereof) resulting from capital sentencing decisions would fuel this evolutionary process. In this respect, this form of juror education would constitute a continual mode of improvement.

As abolishing the death penalty does not seem likely in the near future, we believe that the only responsible course of action lies in responding to the difficulties consistently shown by research on capital sentencing. Inequitable and arbitrary application remains a problem, and juror instructions are not helping to eradicate it. We hope that these recommendations serve as an impetus for policymakers in this area. While juror education is certainly no panacea for the preconceived notions, biases, and beliefs which jurors bring to the deliberation process, it at least holds promise in tempering them, allowing jurors a better chance of reaching a decision based upon informed consideration of the evidence before them.

\section{ACKNOWLEDGEMENT}

The authors thank William Bowers, director of the Capital Juror Project, for assistance with the data collection in Missouri and oversight of the data entry and transcription of the lengthy interviews.

* Corresponding author. 


\section{Notes}

1. Directed by William Bowers, Northeastern University, the Capital Jury Project began in 1990 with funding from the Law and Social Sciences Program of the National Science Foundation, grant NSF SES-9013252. The aim of the project is to gain knowledge about how jurors in capital cases exercise discretion. Missouri was not one of the original states in the study, but was added in 1995. For additional information, see Bowers (1995).

\section{References}

American Bar Association. (1997a). Time out for executions. ABA Journal, 83 (Apr.): 26-30.

American Bar Association. (1997b). Numbers tell the story. ABA Journal, 83 (Oct.): 2027.

Baldus, D.C., Woodworth, G., and Pulaski, C.A. (1994). Reflections on the 'inevitability' of racial discrimination in capital sentencing and the 'impossibility' of its prevention, detection, and correction. Washington and Lee Law Review, 51: 359-430.

Bonita, J. (1996). Risk-needs assessment and treatment. In A.T. Harland (Ed.), Choosing correctional options that work (pp. 18-32). Thousand Oaks, CA: Sage.

Bowers, W.J. (1995). The Capital Jury Project: Rationale, design, and preview of early findings. Indiana Law Journal, 70: 1043-1102.

Brennan, T. (1987). Classification for control in jails and prisons. In D.M. Gottfredson and M. Tonry (eds.), Prediction and classification: Criminal justice decision making (pp. 201-248). Chicago: University of Chicago Press.

Frase, R. (1995). State sentencing guidelines: Still going strong. Judicature, 78(4): 173179.

Goldkamp, J.S. and Gottfredson, M.R. (1985). Policy guidelines for bail. Philadelphia, PA: Temple University Press.

Gottfredson, M. and Gottfredson, D. (1980). Decision making in criminal justice. Cambridge, MA: Ballinger.

Gottfredson, D., Wilkins, L., and Hoffman, P.B. (1978). Guidelines for parole and sentencing: A policy control method. Lexington, MA: Lexington Books.

Jones, P. and Goldkamp, J. (1991). The bail guidelines experiment in Dade County, Miami. Justice System Journal, 14(3): 445-476. 
Sechrest, L. (1987). Classification for treatment. In D.M. Gottfredson and M. Tonry (eds.), Prediction and classification: Criminal justice decision making (pp. 293-322). Chicago: University of Chicago Press.

Wiebush, R.G., Johnson, K., and Wagner, D. (1997). Development of an empiricallybased risk assessment instrument and placement recommendation matrix, final report, prepared for the Maryland Department of Juvenile Justice.

\section{Cases Cited}

Furman v. Georgia, 408 U.S. 238, 309-10 (1972)

Gregg v. Georgia, 428 U.S. 153 (1976)

Jurek v. Texas, 428 U.S. 262, 268-76 (1976)

Lockett v. Ohio, 438 U.S. 586 (1978)

McGautha v. California, 402 U.S. 183 (1971)

McCleskey v. Kemp, 481 U.S. 279 (1987)

Payne v. Tennessee, 501 U.S. 808 (1991)

Proffitt v. Florida, 428 U.S. 242, 251-58 (1976)

Roberts v. Louisiana, 428 U.S. 325, 329 (1976)

Woodson v. North Carolina, 428 U.S. 280, 286 (1976)

Zant v. Stephens, 462 U.S. 862 (1982) 